\title{
Markov-switching analysis of exchange rate pass-through: perspective from Asian
} countries

\begin{abstract}
This study presents a nonlinear pass-through from the exchange rate to domestic prices drawn from a dataset of six Asian countries. Using the Markov-switching model, it is found that there are two regimes. The extent of the pass-through is incomplete and is found to be significantly lower in stable regime states. Domestic prices are sensitive to external factors when inflation uncertainty is higher. Essentially, the pass-through estimates exhibit some variation across countries and regimes. Central banks are credible, but the exchange rate is ineffective as a shock absorber during the unstable regime. We find that the output gap has more influence on inflation when the level of inflation exhibits large and erratic variations. Policymakers need to pay attention during periods of high inflation because consumer prices respond differently when the economy is in a high compared to a low inflation regime.
\end{abstract}

Keyword: Exchange rate pass-through; Inflation; Shock absorber; Structural breaks 